№2, Minsk, Belarus; ${ }^{7}$ JSC BIOCAD, Clinical Development Department, St-Petersburg, Russian Federation

Background: PATERA is an ongoing phase 3 international double-blind, placebo-controlled clinical study of netakimab (NTK) in psoriatic arthritis (PsA) (NCT03598751). Netakimab (NTK) is an anti-interleukin-17A monoclonal antibody approved for psoriasis, ankylosing spondylitis, PsA in Russia and Belarus. Objectives: A subanalysis was performed to define the impact of NTK on PsA activity depending on the presence of axial disease: a subset of patients with inflammatory back pain (IBP) according to self-reported ASAS IBP criteria, 2009 $(\operatorname{IBP}(+)$ was compared to those without IBP $(\operatorname{IBP}(-))$.

Methods: 194 eligible adult patients with PsA fulfilling the CASPAR criteria, with inadequate response to csDMARD or one $\mathrm{TNFi}$, were randomly assigned to receive NTK 120mg or placebo at weeks $0,1,2,4,6,8,10,14,18,22$. Patients with missing values for categorical variables were considered as non-responders in the analysis. For quantitative variables, missing values were replaced using the multiple imputation method.

Results: 97 PsA patients $(\mathrm{N}=54 \mathrm{IBP}(+), \mathrm{N}=43 \mathrm{IBP}(-))$ received NTK. Both subpopulations were comparable in gender, age and PsA activity at baseline. The treatment led to a pronounced decline in PsA activity in both subpopulations, significant differences between arms were observed only in DAPSA remission and very low disease activity (VLDA) at week 24 (Figure 1A). Changes from baseline in DAS28-CRP were consistent between IBP(+) and IBP(-) patients with a rapid decline during the first month with further improvement up to week 24 (Figure 1B). A similar trend was observed PsA-specific composite responder index (PSARC) (data not shown). A comparable percentage of IBP(+) and IBP(-) patients achieved PSARC at each timepoint of evaluation with $87 \%$ and $86 \%$ of responders respectively at week 24 .

Conclusion: NTK significantly improved PsA activity regardless of the presence of IBP.
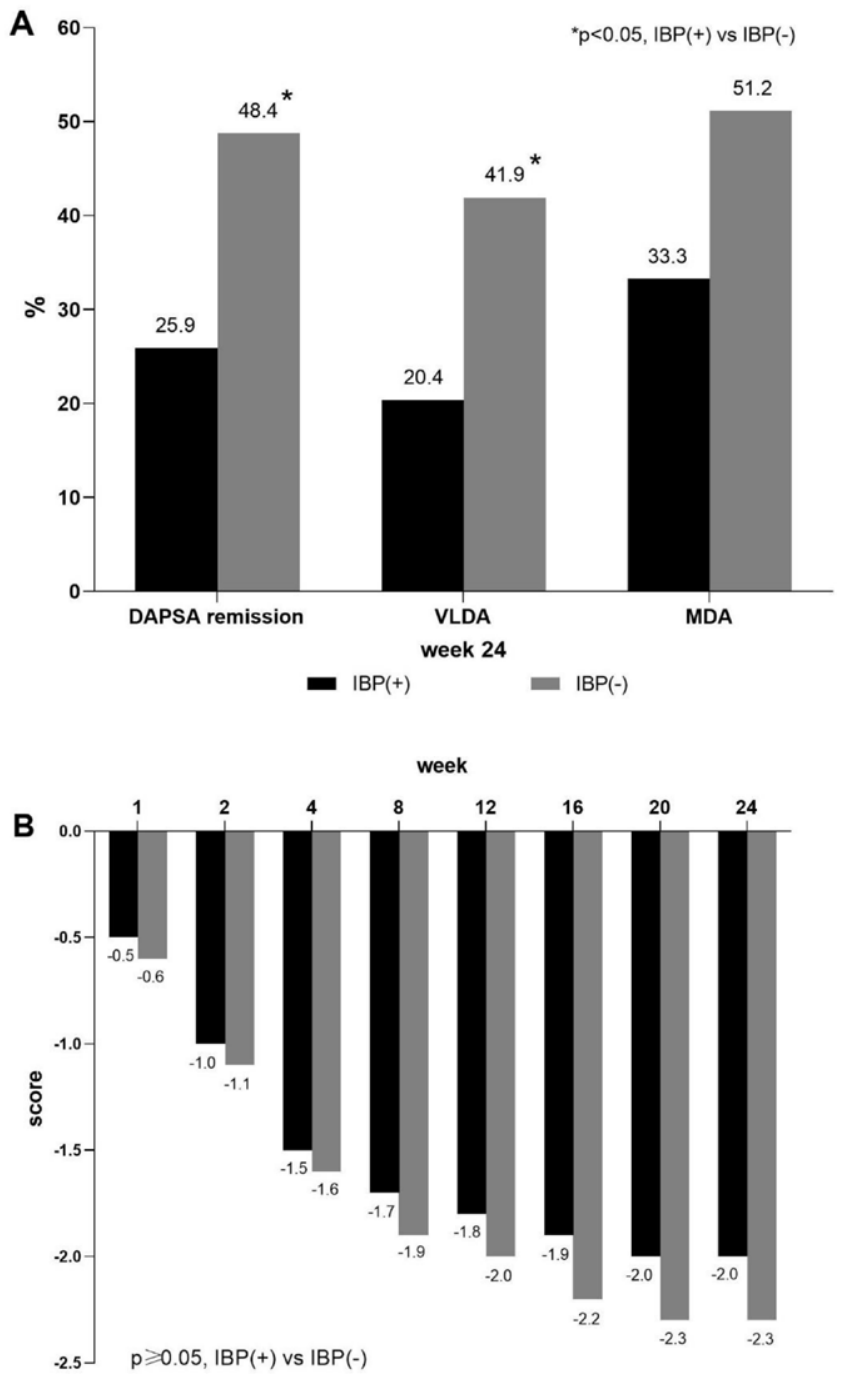

- $\operatorname{IBP}(+)$
Figure 1. PsA activity after 24-week treatment with NTK. (A) Percentage of patients with DAPSA remission (0-4), very low disease activity (VLDA), minimal disease activity (MDA) at week 24; (B) change from baseline in DAS28-CRP

Acknowledgements: This study was sponsored by JSC BIOCAD.

Disclosure of Interests: Tatiana Korotaeva Speakers bureau: Abbvie, Biocad, Eli Lilly, Johnson \& Johnson, Janssen, Novartis, Pfizer, UCB, Inna Gaydukova Speakers bureau: Abbvie, Biocad, Eli Lilly, MSD, Novartis, Pfizer, Sandoz, V Mazurov: None declared, Aleksey Samtsov: None declared, Vladislav Khayrutdinov: None declared, Andrey Bakulev: None declared, Alena Kundzer: None declared, Nikolaj Soroka: None declared, Anna Eremeeva Employee of: Biocad. DOI: 10.1136/annrheumdis-2021-eular.1555

\section{POS1044 1 EFFECT OF SECUKINUMAB VERSUS ADALIMUMAB ON ACR CORE COMPONENTS AND HEALTH-RELATED QUALITY OF LIFE IN PATIENTS WITH PSORIATIC ARTHRITIS: RESULTS FROM THE EXCEED STUDY}

P. Goupille $^{1}$, F. Behrens ${ }^{2}$, L. C. Coates ${ }^{3}$, J. Gratacos-Masmitja ${ }^{4}$, P. J. Mease ${ }^{5}$, D. D. Gladman ${ }^{6}$, P. Nash ${ }^{7}$, A. Kavanaugh ${ }^{8}$, R. Martin ${ }^{9}$, W. Bao ${ }^{9}$, C. Gaillez ${ }^{10}$, I. Mcinnes ${ }^{11}$. ${ }^{1}$ University of Tours, Department of Rheumatology and INSERMCIC1415, Tours, France; ${ }^{2}$ Goethe University, Rheumatology University Hospital and Fraunhofer Institute for Molecular Biology and Applied Ecology IME, Branch for Translational Medicine and Pharmacology TMP and Fraunhofer Cluster of Excellence for Immune-Mediated Diseases CIMD, Frankfurt, Germany; ${ }^{3}$ University of Oxford, Nuffield Department of Orthopaedics, Rheumatology and Musculoskeletal Sciences, Oxford, United Kingdom; ${ }^{4}$ University Hospital Parc Taulí, Sabadell, Universitat Autònoma de Barcelona, Rheumatology Department, Barcelona, Spain; ${ }^{5}$ Swedish Medical Centre/Providence St. Joseph Health and University of Washington, Rheumatology Research Division, Seattle, United States of America; ${ }^{6}$ Toronto Western Hospital, University of Toronto, Schroeder Arthritis Institute, Ontario, Canada; ${ }^{7}$ Griffith University, Department of Medicine, Brisbane, Australia; ${ }^{8}$ University of California San Diego, School of Medicine, Rheumatology, Allergy, Immunology Division, La Jolla, United States of America; ${ }^{9}$ Novartis Pharmaceuticals Corporation, Immunology, Hepatology and Dermatology, East Hanover, United States of America; ${ }^{10}$ Novartis Pharma AG, Immunology, Hepatology and Dermatology, Basel, Switzerland; ${ }^{11}$ University of Glasgow, Institute of Infection, Immunity and Inflammation, College of Medical, Veterinary and Life Sciences, Glasgow, United Kingdom

Background: EXCEED (NCT02745080) was the first fully blinded head-to-head trial to evaluate the efficacy and safety of secukinumab (SEC) versus (vs) adalimumab (ADA) monotherapy in patients with active psoriatic arthritis (PsA) with a primary endpoint of American College of Rheumatology (ACR) 20 at Week 52. Although SEC narrowly missed statistical significance for superiority vs ADA numerically higher response for other musculoskeletal endpoints and composite indices were observed with SEC. ${ }^{1}$

Objectives: To explore the effect of SEC and ADA on ACR core components, function and Health-related Quality of Life (HRQoL) outcomes.

Methods: Patients were randomised $1: 1$ to receive SEC $300 \mathrm{mg}(\mathrm{N}=426)$ subcutaneous (s.c.) at baseline, Week 1-4, followed by every 4 weeks until Week 48 or ADA $40 \mathrm{mg}(\mathrm{N}=427)$ s.c. at baseline followed by same dosing every 2 weeks until Week 50. The primary, key secondary and some exploratory endpoints at Week 52 were previously reported. ${ }^{1}$ A supportive analysis for ACR50 response using logistic regression model and trimmed means model for Health Assessment Questionnaire-Disability Index (HAQ-DI) with gender and smoking status as factors was performed to adjust for imbalances in baseline characteristics. An exploratory analysis of ACR core components with SEC vs ADA at Week 52 was conducted using a mixed-effects repeated measures model that included tender and swollen joint counts, patient and physician global assessment, PsA pain (VAS) and erythrocyte sedimentation rate. HRQoL variables were also exploratory and assessed based on Short Form Health Survey Physical/Mental Component Summary (SF-36 PCS/MCS) scores and Dermatology Life Quality Index (DLQI).

Results: The demographic and baseline disease characteristics were comparable across treatment groups, except for an imbalance in sex (females: $51.2 \%$ vs $46.4 \%$ ) and smoking status (yes: $21.8 \%$ vs $17.8 \%$ ) in SEC and ADA group, respectively. At Week 52, ACR50 responses were $49.0 \%$ and $44.8 \%(P=0.0929)$ and HAQ-DI mean change from baseline were -0.69 and $-0.58 \quad(P=0.0314)$ in SEC and ADA treatment groups, respectively after adjusting for gender and smoking status. No major difference across ACR core components was observed in both treatment groups at Week 52 (Table 1). At Week 52, SEC presented similar improvement in SF-36 PCS/MCS score and numerically higher improvement in DLQI compared to ADA (Figure 1).

Conclusion: Secukinumab provided similar improvements in ACR core components and SF-36 based quality of life at Week 52 with adalimumab. Greater improvement in HAQ-DI response and DLQI was demonstrated with secukinumab compared to adalimumab. 
REFERENCES:

[1] McInnes IB, et al. Lancet. 2020; 395:1496-505.

Table 1. ACR Core Components at Week 52

\begin{tabular}{llll}
\hline Variables & Secukinumab $300 \mathrm{mg}$ & Adalimumab $40 \mathrm{mg}$ & $P$-value \\
& $(\mathrm{N}=426)$ & \multicolumn{2}{c}{$(\mathrm{N}=427)$} \\
\hline & $\mathrm{BL}$, mean & $\mathrm{LSM}$ change $\mathrm{BL}$, mean & $\mathrm{LSM}$ change \\
$\pm \mathrm{SE}$ & from $\mathrm{BL} \pm \mathrm{SE} \pm \mathrm{SE}$ & from $\mathrm{BL} \pm \mathrm{SE}$ \\
\hline
\end{tabular}

Tender joint score

$19.4 \pm 13.86-14.27 \pm 0.4420 .6 \pm 14.81-13.90 \pm 0.450 .5549$

(based on 78 joints)

Swollen joint score

$9.7 \pm 7.30 \quad-8.41 \pm 0.19 \quad 10.2 \pm 7.86 \quad-8.06 \pm 0.20 \quad 0.1962$

(based on 76 joints)

Patients global assessment $\quad 64.0 \pm 19.67-33.81 \pm 1.14 \quad 61.9 \pm 20.75-31.61 \pm 1.190 .1825$ Physicians global assessment60.0 $\pm 17.12-46.24 \pm 0.8061 .4 \pm 15.92-43.63 \pm 0.840 .0243$ Psoriatic arthritis pain (VAS) $58.6 \pm 23.49-30.21 \pm 1.18 \quad 57.9 \pm 22.42-29.44 \pm 1.230 .6500$ Erythrocyte sedimentation $\quad 23.8 \pm 18.93-9.63 \pm 0.62 \quad 23.9 \pm 17.99-9.28 \pm 0.64 \quad 0.7029$ rate $(\mathrm{mm} / \mathrm{h})$

LS mean and nominal $P$-values are from a mixed-effects repeated measures model with treatment group, analysis visit as factors, weight and BL score as covariates, and by treatment and $\mathrm{BL}$ score as interaction terms, unstructured covariance structure. ACR, American College of Rheumatology; BL, baseline; LSM, least squares mean; N, total number of randomised patients; SE, standard error; VAS, visual analogue scale

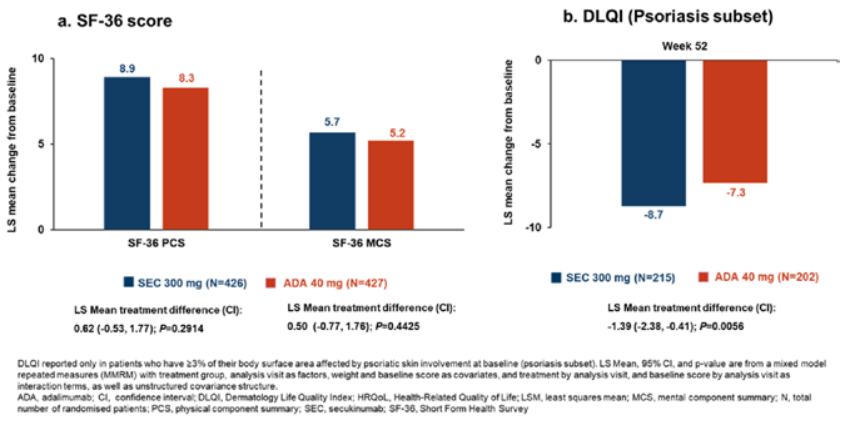

Figure 1. HRQoL Analysis at Week 52

Disclosure of Interests: Philippe Goupille Speakers bureau: AbbVie, Amgen, Biogen, BMS, Celgene, Chugai, Janssen, Eli Lilly, Medac, MSD, Nordic Pharma Novartis, Pfizer, Sanofi and UCB, Consultant of: AbbVie, Amgen, Biogen, BMS Celgene, Chugai, Janssen, Eli Lilly, Medac, MSD, Nordic Pharma, Novartis, Pfizer, Sanofi and UCB, Grant/research support from: AbbVie, Amgen, Biogen, BMS, Celgene, Chugai, Janssen, Eli Lilly, Medac, MSD, Nordic Pharma, Novartis, Pfizer, Sanofi and UCB, Frank Behrens Paid instructor for: Eli Lilly, Consultant of: Pfizer, AbbVie, Sanofi, Eli Lilly, Novartis, Genzyme, Boehringer Ingelheim, Janssen, MSD, Celgene, Roche and Chugai, Grant/research support from: Pfizer, Janssen, Chugai, Celgene and Roche, Laura C Coates Consultant of: AbbVie, Amgen, Boehringer Ingelheim, Biogen, BMS, Celgene, Domain, Eli Lilly, Gilead, GSK, Janssen, Medac, Novartis, Pfizer, Serac and UCB, Grant/research support from: AbbVie, Amgen, Celgene, Eli Lilly, Janssen, Novartis, Pfizer and UCB, Jord Gratacos-Masmitja Speakers bureau: AbbVie, Amgen, BMS, Celgene, Janssen, Eli Lilly, Novartis and Pfizer, Consultant of: AbbVie, Amgen, BMS, Celgene, Janssen, Eli Lilly, Novartis and Pfizer, Grant/research support from: AbbVie, Amgen, BMS, Celgene, Janssen, Eli Lilly, Novartis and Pfizer, Philip J Mease Speakers bureau: AbbVie, Amgen, Genentech, Janssen, Eli Lilly, Merck, Novartis, Pfizer, and UCB, Consultant of: AbbVie, Amgen, Bristol-Myers Squibb, Boehringer Ingelheim, Galapagos, Celgene, Genentech, Gilead, Janssen, Eli Lilly, Novartis, Pfizer, SUN Pharma, and UCB, Grant/research support from: AbbVie, Amgen, Bristol-Myers Squibb, Celgene, Galapagos, Genentech, Gilead, Janssen, Eli Lilly, Merck, Novartis, Pfizer, SUN Pharma, and UCB, Dafna D Gladman Consultant of: Amgen, AbbVie, BMS, Celgene, Eli Lilly, Gilead, Galapagos, Janssen, Novartis, Pfizer and UCB, Grant/research support from: Amgen, AbbVie, Celgene, Eli Lilly, Janssen, Novartis, Pfizer and UCB, Peter Nash Speakers bureau: Novartis, Abbvie, Roche, Pfizer, BMS, Janssen, Celgene, UCB, Eli Lilly, MSD, Sanofi, Gilead, Consultant of: Novartis, Abbvie, Roche, Pfizer, BMS, Janssen, Celgene, UCB, Eli Lilly, MSD, Sanofi, Gilead, Grant/research support from: Novartis, Abbvie, Roche, Pfizer, BMS, Janssen, Celgene, UCB, Eli Lilly, MSD, Sanofi, Gilead, Arthur Kavanaugh Consultant of: AbbVie, Amgen, Celgene, Eli Lilly, Janssen, Novartis, and UCB, Grant/research support from: AbbVie, Amgen, Celgene, Eli Lilly, Janssen, Novartis, and UCB, Ruvie Martin Shareholder of: Novartis, Employee of: Novartis, Weibin
Bao Shareholder of: Novartis, Employee of: Novartis, Corine Gaillez Shareholder of: Novartis and BMS, Employee of: Novartis, lain McInnes Speakers bureau: AbbVie, Amgen, Bristol-Myers Squibb, Celgene, Janssen, Eli Lilly, Novartis, Pfizer, and UCB, Consultant of: AbbVie, Amgen, Bristol-Myers Squibb, Celgene, Janssen, Eli Lilly, Novartis, Pfizer, and UCB, Grant/research support from: AbbVie, Amgen, Bristol-Myers Squibb, Celgene, Janssen, Eli Lilly, Novartis, Pfizer, and UCB. DOI: 10.1136/annrheumdis-2021-eular.1562

\section{POS1045 \\ IXEKIZUMAB EFFICACY ON SPINAL PAIN, DISEASE ACTIVITY AND QUALITY OF LIFE IN PATIENTS WITH PSORIATIC ARTHRITIS PRESENTING WITH SYMPTOMS SUGGESTIVE OF AXIAL INVOLVEMENT}

A. Deodhar ${ }^{1}$, D. D. Gladman ${ }^{2}$, R. Bolce ${ }^{3}$, D. Sandoval ${ }^{3}$, S. Y. Park ${ }^{3}$, S. Liu Leage $^{3}$, P. Nash ${ }^{4}$, D. Poddubnyy ${ }^{5} .{ }^{1}$ Oregon Health and Science University, School of Medicine, Oregon, United States of America; ${ }^{2}$ University of Toronto, Krembil Research Unit, Toronto, Canada; ${ }^{3}$ Eli Lilly and Company, Lilly Corporate Center, Indianapolis, United States of America; ${ }^{4}$ Griffith University, School of Medicine, Brisbane, Australia; ${ }^{5}$ Charité University Hospital, Department of Gastroenterology, Infectiology and Rheumatology, Berlin, Germany

Background: Many patients with psoriatic arthritis (PsA) experience back pain and stiffness, which may suggest axial involvement [1]. The prevalence of axial involvement in PsA varies between $25-70 \%$ [2]. Ixekizumab (IXE), a monoclonal antibody with high affinity for IL17-A, has been studied in Phase 3 trials in patients with PsA (SPIRIT-P1 [Biologic-naïve; NCT01695239] and SPIRIT-P2 [Inadequate response or intolerant to 1 or 2 TNF inhibitors (TNFi); NCT02349295]) [3] [4].

Objectives: To determine the efficacy of IXE up to 52 weeks (Wks) in reducing axial symptoms in patients with active PsA presenting with symptoms suggestive of axial involvement.

Methods: This post-hoc analysis included data from two subpopulations of patients with PsA (pooled SPIRIT-P1 and -P2). Symptoms suggestive of axial involvement were defined as Bath Ankylosing Spondylitis Disease Activity Index (BASDAI) Q2 (back pain) $\geq 4$, and an average of Q5 + Q6 (intensity and duration of morning stiffness in the spine) $\geq 4$ at baseline. Patients included in the sensitivity analysis subgroup 1 were, in addition to the above-mentioned overall analysis criteria, $<45$ years of age, while patients included in sensitivity analysis subgroup 2 were aged $<45$ but also had elevated C-reactive protein (CRP) $(>5 \mathrm{mg} / \mathrm{l})$ at baseline. Efficacy of IXE was analysed using BASDAI questions, total BASDAI, mBASDAI (without Q3), and Ankylosing Spondylitis Disease Activity Score (ASDAS) change from baseline, as well as BASDAI50 response and Short-Form-36 physical component summary (SF-36 PCS) improvement, at Wks 16, 24 and 52. Treatment comparison was done using logistic regression for BASDAI50, and analysis of covariance (ANCOVA) model for other endpoints. Missing data for binary and continuous endpoints were imputed by non-responder imputation and modified baseline observation carried forward (mBOCF), respectively. Results: A total of 313 patients (placebo (PBO), $N=151$; IXE Q4W, $N=162$ ) me the overall analysis inclusion criteria. Baseline values for BASDAI and ASDAS related endpoints were balanced across treatment arms (Table 1). Improvement in axial symptoms were significantly greater in patients treated with IXE compared to PBO at Wks 16 and 24 (Figure 1. next page) Improvement in quality of life (QoL) measures (SF-36 PCS) were also significantly greater in patients treated with IXE compared to PBO at Wks 16 and 24 (Table 1). Similar results were observed for patients $<45$ years, and in patients $<45$ years with CRP $>$ $5 \mathrm{mg} / \mathrm{l}$ at baseline (sensitivity analysis, data not shown).

Conclusion: IXE is effective in reducing axial symptoms and improving QoL in patients with active PsA presenting with symptoms suggestive of axial involvement.

Table 1. Baseline values and change from baseline (mBOCF) in the overall analysis population at Wks 16, 24 and 52 for BASDAl and ASDAS related endpoints in patients with PsA and axial pain. Data presented as mean (SD) unless otherwise specified. $\neq \mathrm{p}<0.001$ vs PBO.

\begin{tabular}{|c|c|c|c|c|c|}
\hline & $\begin{array}{l}\text { PBO } \\
(\mathrm{N}=151)\end{array}$ & & $\begin{array}{l}\text { IXE Q4W } \\
(\mathrm{N}=162)\end{array}$ & & \\
\hline Baseline values & Wk 0 & & Wk 0 & & \\
\hline BASDAI & $6.7(1.4)$ & & $6.6(1.3)$ & & \\
\hline Q2 & $7.0(1.7)$ & & $6.7(1.7)$ & & \\
\hline Q5 & $7.3(1.5)$ & & $7.3(1.5)$ & & \\
\hline Q6 & $5.8(2.7)$ & & $5.5(2.7)$ & & \\
\hline mBASDAI & $6.7(1.4)$ & & $6.6(1.3)$ & & \\
\hline ASDAS & $3.7(0.8)$ & & $3.6(0.9)$ & & \\
\hline SF-36 PCS & $29.9(7.4)$ & & $30.0(8.4)$ & & \\
\hline Outcome measures & Wk 16 & Wk 24 & Wk 16 & Wk 24 & Wk 52 \\
\hline ASDAS & $-0.4(0.8)$ & $-0.4(0.8)$ & $-1.2(1.2) \ddagger$ & $-1.3(1.2) \ddagger$ & $-1.4(1.2)$ \\
\hline BASDAI50, n (\%) & $16(11)$ & $12(8)$ & $51(32) \ddagger$ & 61 (38)‡ & $64(40)$ \\
\hline mBASDAI & $-1.0(1.7)$ & $-1.0(1.7)$ & $-2.1(2.1) \ddagger$ & $-2.4(2.3) \ddagger$ & $-2.7(2.1)$ \\
\hline SF-36 PCS & 1.9 (7.3) & $2.0(6.9)$ & $5.8(8.8) \ddagger$ & $6.8(9.9) \ddagger$ & $8.8(9.5)$ \\
\hline
\end{tabular}

